early modern science by pointing to specific connexions. Secondly, it gives a much fuller and more informed treatment of the fifteenth and sixteenth century developments than is usual. Thirdly, it rightly emphasizes the very deep ancient, mediaeval, and Renaissance influences at work on men like Galileo, Harvey, and Newton.

One can, however, disagree with the author on various points of detail and, indeed, on certain major issues. It seems to me that non-Aristotelian modes of scientific explanation and causality are not adequately dealt with. In fact, very little is said of the traditions of magic and pseudo-science, though it is becoming increasingly apparent that these had a more significant role in the development of "modern science" than had been realized. The book is challenging, however, and one hopes that both historians and philosophers of science read it, for, among other things, it provides a richer range of examples than is usually accounted for. It is scrupulously documented, has an excellent working bibliography, and is well indexed.

Charles B. SchmitT

\section{Plant Biosystematics}

Taxonomy, Phytogeography and Evolution. Edited by D. H. Valentine. Pp. $x i+431$. (Academic: New York and London, October 1972.) $£ 7.20$.

THIs volume records the proceedings of a symposium held by the Linnean and Botanical Societies of the British Isles in association with the International Organization of Plant Biosystematists.

The papers included vary greatly in nature and approach: some deal with certain small groups (for example, Epilobium, Alchemilla, Nothofagus), while others discuss whole families (Combretaceae) or life forms (weeds). Some consider comparatively small circumscribed areas (for example, Canary Islands) and others vast land masses from Europe to Africa, North to South America or the Arctic and the Cool Temperate Zone. The emphasis in most of the twenty-five contributions, however, is evolutionary and taxonomic, while the geological and geographic aspects receive much less attention.

The topics considered include endemism, vicariousness, disjunction, connexions and correspondences between floras of different areas, the role of hybridization, the significance of apomixis and the migration of both wild and cultivated species.

On the methodological side, some attention is given to computer mapping and analysis, but few of the papers actually deal with the classification of species into floral elements on a geographical basis (chorology).

Although biology found its begin- nings in a taxonomic and distributional approach to variation, detailed information on distribution in relation to evolution is sadly lacking. Admittedly, such information is accumulating, as witnessed by this symposium, but there can be few areas of biology in which there is less agreement and uniformity with regard to what data should be recorded, the manner of their presentation and, especially, guide-lines for their explanation. To some extent, this diffuseness reflects the recent preoccupation with molecular and cellular levels of organization. But the complexities of population structure and the magnitude of spatial and temporal organizations in nature present formidable problems of analysis and interpretation.

This valuable volume is an expression of the revival of interest in macrobiology which, hopefully, is now poised to proceed, if not as quickly, then as far as studies within the individual have done in recent years. Since its eminent contributors, burying old antagonisms and animosities, recognize the need for a combined attack utilizing the descriptive and analytical methods of many disciplines, this hope is more than pious. The only cause for concern lies in the departure from neo-Darwinian attitudes to evolution which commonly attends considerations of big biological problems, large areas, long periods of time and relatively unrelated organisms which one can neither cross nor, therefore, adequately classify.

\section{K. R. LEWIS}

\section{Ovary Anatomy}

Comparative Morphology of the Mammalian Ovary. By Harland W. Mossman and Kenneth L. Duke. Pp. xxviii +461. (University of Wisconsin: Madison, June 1973.) \$28.

THIs is a well-organized, comprehensive account of ovarian morphology containing much unpublished information collected by the authors. After chapters dealing with the gross anatomy and microscopic structure of the ovary an account is given of the development of the ovary. Chapter 4 describes changes in the ovary during the life cycle of a representative species (the red squirrel); the ovaries in this animal are small enough to permit a study of serial sections and the different cell types are easily distinguishable. However, these considerations also apply to the guineapig, which would be a better example to use since we know more about ovarian hormone production in this species. Chapter 6 is a readable account of comparative morphology, since most of the details of ovarian morphology in various taxonomic groups are presented in a series of synoptic tables and supplementary notes. In this way the general trends become apparent and are not obscured by too much detail. In a field where there is much confusion about terminology the glossary defining the various terms which are used is extremely helpful. Those interested only in the human ovary will find chapter 5 and the chapter on "Features and Problems Associated with the Ovary", in which matters such as the origin of follicular fluid, follicular atresia, anovular and polyovular follicles are considered, both informative and interesting. This is an admirable book, profusely illustrated with diagrams and photographs, and will be invaluable to the comparative anatomist and endocrinologist.

\section{K. FOTHERBY}

\section{Pollination}

The Pollination of Flowers. By Michael Proctor and Peter Yeo. Pp. $418+200$ photographs. (William Collins: London, April 1973.) $£ 4$.

IT is inevitable that a book on this sadly neglected subject should contain much information on the structural modifications of flowers and insects associated with the evolution of pollination mechanisms. In these circumstances a book can easily become a catalogue of such relationships. The authors of this volume, however, have covered the morphological aspects of pollination in a brief yet systematic way, much information being summarized in tabular and diagrammatic form. Consequently much space is devoted to such problems as the respective roles of scent and sight in the behaviour patterns of the insect visitors. Of particular interest is the discussion of colour vision in bees and its significance in flower discrimination.

Undoubtedly the orchids represent the most highly adapted group of plants with respect to their pollination mechanisms, and a chapter is devoted to the British species. In the orchid genus Ophrys, the insect/flower relationship becomes little less than bizarre, the flower having evolved scent, visual and tactile modifications which release copulatory behaviour in the male Halictus solitary bee. The authors regard this type of modification as a form of parasitism upon the insect vectors via their behavioural responses.

As Darwin was well aware, the study of pollination mechanisms reveals how intense the pressures of natural selection can be, and in their final chapter the authors consider the development of pollination strategies in relation to the evolution of both flowering plants and insects.

The book is packed with interesting information and contains many of Michael Proctor's excellent photographs. PETER D. MOORE 